\title{
Inhibitory Effects of Astragalus Polysaccharide on Proliferation of Human Lung Adenocarcinoma H1299 Cells via the Toll-Like Receptor 4/Myeloid Differentiation Factor 88/Nuclear Factor-Kappa B Signaling Pathway
}

\author{
JING CHEN ${ }^{1}$, DAN TAO ${ }^{1}$, D. Y. YANG ${ }^{1}$, Y. JIANG ${ }^{1}$ AND Y. Y. LONG ${ }^{\text {* }}$ \\ Department of Radiation Oncology, ${ }^{1}$ Chongqing Key Laboratory of Translational Research for Cancer Metastasis and \\ Individualized Treatment, Chongqing University Cancer Hospital, Chongqing Cancer Institute, Chongqing Cancer Hospital, \\ Shapingba, Chongqing 400030, China
}

Chen et al.: Influence of Astragalus Polysaccharide on Lung Adenocarcinoma

\begin{abstract}
To assess the inhibitory effects of Astragalus polysaccharide on the proliferation of human lung adenocarcinoma $\mathrm{H1299}$ cells via the toll-like receptor 4/myeloid differentiation factor 88 /nuclear factor-kappa B signaling pathway. $\mathrm{H1299}$ cells were treated with different concentrations of Astragalus polysaccharide. After $24 \mathrm{~h}$ and $48 \mathrm{~h}$, cell counting kit-8 assay was employed to measure the cell proliferation. The effects of Astragalus polysaccharide $(25 \mu \mathrm{g} / \mathrm{ml})$ on the invasion ability, migration ability and apoptosis of $\mathrm{H1299}$ cells were determined by transwell assay, wound healing and apoptosis assays, respectively. The changes in expressions of toll-like receptor $4 /$ myeloid differentiation factor 88 /nuclear factor-kappa B signaling pathway-related proteins in $\mathrm{H} 1299$ cells after $48 \mathrm{~h}$ of treatment with $25 \mu \mathrm{g} / \mathrm{ml}$ Astragalus polysaccharide were detected by western blotting. Astragalus polysaccharide inhibited the proliferation of $\mathrm{H1299}$ cells in a dose-dependent manner $(\mathbf{p}<\mathbf{0 . 0 5})$. The migration rate of $\mathrm{H1299}$ cells treated with $25 \mu \mathrm{g} / \mathrm{ml}$ Astragalus polysaccharide was significantly lower than that of blank control group. After treatment with $25 \mu \mathrm{g} / \mathrm{ml}$ Astragalus polysaccharide, the number of $\mathrm{H1299}$ cells invading through Matrigel into the lower chamber significantly reduced. The apoptosis rate of $\mathrm{H} 1299$ cells treated with $25 \mu \mathrm{g} / \mathrm{ml}$ Astragalus polysaccharide was significantly higher than that of blank control group. Toll-like receptor 4 , myeloid differentiation factor 88 and nuclear factor-kappa B protein expression levels in $\mathrm{H1299}$ cells treated with Astragalus polysaccharide $(25 \mu \mathrm{g} / \mathrm{ml})$ for $48 \mathrm{~h}$ were significantly lower than those of blank control group. Astragalus polysaccharide can inhibit the proliferation, migration and invasion of $\mathrm{H1299}$ cells and induce apoptosis, possibly being related to the reduction of toll-like receptor 4 , myeloid differentiation factor 88 and nuclear factor-kappa $B$ protein expressions in cells.
\end{abstract}

Key words: Toll-like receptor 4/myeloid differentiation factor 88/nuclear factor-kappa B signaling pathway, Astragalus polysaccharide, human lung adenocarcinoma H1299 cell proliferation

Lung cancer ranks first in the mortality of cancers worldwide and according to statistics, Non-Small Cell Lung Cancer (NSCLC) accounts for more than $80 \%$ of all cases. Considerable possibilities for invasion and metastasis exist and metastasis and recurrence are the major causes of death ${ }^{[1]}$. Therefore, identifying the mechanism of invasion and metastasis and investigating the prevention and treatment strategies of lung cancer are of great essentiality. At present, chemotherapy remains an important means of treatment of malignant tumors. For instance, platinum-based doublet chemotherapy

*Address for correspondence E-mail: lonky_007@163.cm

January-February 2022 is considered as a valuable standard regimen for postoperative adjuvant treatment of NSCLC and firstline treatment of advanced NSCLC in clinical practice. However, acquired resistance to conventional cytotoxic drugs easily occurs due to their excessive damage to This is an open access article distributed under the terms of the Creative
Commons Attribution-NonCommercial-ShareAlike 3.0 License, which
allows others to remix, tweak, and build upon the work non-commercially,
as long as the author is credited and the new creations are licensed under
the identical terms

Accepted 10 January 2022

Revised 16 June 2021

Received 18 May 2020

Indian J Pharm Sci 2022;84(1):35-40 
normal cells, so that clinical efficacy is also limited ${ }^{[2,3]}$. Considering that molecular targeted agents have exhibited great therapeutic value for NSCLC in recent years, continuing to develop new chemotherapeutic agents or expanding the clinical indications of certain prescription drugs will bring new hopes for patients with malignancies. As one of the main active constituents in the dried root of Astragalus membranaceus, Astragalus Polysaccharide (APS) is a water-soluble polysaccharide formed by means of extraction, concentration and purification, and consisted of glucose, hexuronic acid, fructose, galactose, arabinose, etc., ${ }^{[4]}$. APS has certain effects such as anti-tumor, anti-virus, anti-oxidative stress and anti-apoptosis. Lipopolysaccharide (LPS), as the main ingredient of endotoxin, is capable of promoting the proliferation and metastasis of various cancer cells through multiple ways during cancer cell growth and metastasis induced by chronic inflammation, whose mechanism of action is described as follows. The intracellular Toll-Like Receptor 4 (TLR4) is activated by LPS, which initiates the Myeloid Differentiation Factor 88 (MyD88)-dependent pathway, leading to the activation of transcription factors such as Nuclear Factor-Kappa B (NF- $\kappa B$ ) and then NF- $\mathrm{BB}$ migrates into the nucleus, resulting in the activation of multiple cancer-related target genes ${ }^{[5-7]}$. This study aimed to investigate the inhibitory effects of APS on the proliferation of Human Non-Small Cell Lung Carcinoma Cell Line (H1299) cells via the TLR4/ MyD88/NF- $\kappa B$ signaling pathway.

\section{MATERIALS AND METHODS}

\section{Cell lines and main reagents:}

Human lung adenocarcinoma H1299 cells (Shanghai Cell Bank ofChinese Academy ofSciences),APS (Guilin Pharma), cell proliferation and cytotoxicity assay kits [Cell Counting Kit-8 (CCK-8), Dojindo Laboratories, Japan], cell invasion assay-related Matrigel (BD Biosciences, Bedford, Massachusetts, United States of America (USA)), transwell chambers (Corning, USA), Annexin V-Fluorescein Isothiocyanate (FITC) kits (NeoBioscience Technology Co., Ltd., China), TLR4,

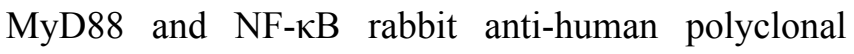
antibodies (Abcam, USA), and horseradish peroxidaselabeled secondary antibodies (Beijing Zhongshan Golden Bridge Biotechnology Co., Ltd., China) were used.

\section{Cell culture:}

The frozen H1299 cells were thawed within 1 min by rapid agitation in a water bath at $37^{\circ}$. Subsequently, the samples were aspirated by a pipette into a centrifuge tube $(15 \mathrm{ml})$, followed by addition of $5 \mathrm{ml}$ of complete medium and thorough mixing. After centrifugation at $1500 \mathrm{rpm}$ for $5 \mathrm{~min}$, the medium was discarded and $5 \mathrm{ml}$ of complete medium was added. After being pipetted evenly, the cells were routinely cultured in a new culture flask in a constant temperature incubator.

\section{Detection of effect of APS on proliferation of $\mathrm{H1299}$ cells by CCK-8 assay:}

H1299 cells in the logarithmic growth phase were digested by $0.25 \%$ trypsin solution and harvested and inoculated into a 96-well plate at a concentration of $20 \times 10^{4}$ cells $/ \mathrm{ml}$, with $100 \mu \mathrm{l}$ of cell suspension in each well. After the cells adhered to the wall for $12 \mathrm{~h}$, the culture medium containing different concentrations of APS was added to intervene in the cells in experimental group for $24 \mathrm{~h}$ and $48 \mathrm{~h}$, with 3 replicates in each group. After the corresponding incubation time, $10 \mu \mathrm{l}$ of CCK-8 reagent at a concentration of $5 \mathrm{mg} / \mathrm{ml}$ was added to each well, followed by incubation for $1-2 \mathrm{~h}$. The Optical Density (OD) of each well was measured at a wavelength of $450 \mathrm{~nm}$ using a microplate reader. The survival rate of cells in control wells was deemed $100 \%$, based on which the survival rate of APS-treated cells in other wells was calculated: Survival rate $(\%)=\left(\mathrm{OD}_{\text {Experimental well }}-\mathrm{OD}_{\text {Blank well }}\right) /\left(\mathrm{OD}_{\text {Control well }}-\mathrm{OD}_{\text {Blank }}\right.$ well $) \times 100 \%$.

\section{Determination of effect of APS on migration of H1299 cells by wound healing assay:}

H1299 cells were inoculated into a 6-well plate at a density of $5 \times 10^{5}$ cells/well. When the cells were fused, a sterile pipette tip $(10 \mu \mathrm{l})$ was used to uniformly scratch each well. After floating cells were washed off with preheated phosphate buffer, normal medium and medium containing $25 \mu \mathrm{g} / \mathrm{ml}$ APS were added to the wells and cell gaps in each well were photographed. After the 6-well plate was cultured in the constant temperature incubator for $48 \mathrm{~h}$, wound healing status was observed and cell gaps at the bottom of each well were photographed again to observe whether there is a difference in the migration distance of H1299 cells in the presence or absence of APS intervention.

\section{Determination of effect of APS on invasion of H1299 cells by transwell assay:}

Matrigel at a concentration of $50 \mu \mathrm{g} / \mathrm{ml}$ was added into a transwell chamber with a polycarbonate membrane pore size of $8.0 \mu \mathrm{m}$ and the liquid should cover the 
bottom of the chamber in a flat and even way. Then the chamber was placed in the constant temperature incubator at $37^{\circ}$ for about $5 \mathrm{~h}$. After the Matrigel solidified, H1299 cells were digested and harvested for counting and then prepared into cell suspension at a concentration of $5 \times 10^{5}$ cells $/ \mathrm{ml}$. Then cell suspension $(100 \mu \mathrm{l})$ was added into each chamber. The culture medium with and without $30 \mu \mathrm{g} / \mathrm{ml}$ APS were added into the lower transwell chamber and the culture plate was cultured in the constant temperature incubator at $37^{\circ}$ for $48 \mathrm{~h}$. After that, the culture medium in the upper and lower chambers was aspirated away, $250 \mu \mathrm{l}$ of 0.1 $\%$ crystal violet solution was added for staining for 10-15 min and the Matrigel in the upper chamber was gently wiped off with a cotton swab. Subsequently, the cells in 5 fields of view (top, middle, bottom, left and right) in each well were observed under a microscope, the number of invading cells was counted and its difference with or without APS intervention was detected.

\section{Determination of effect of APS on apoptosis of H1299 cells by apoptosis assay:}

H1299 cells were treated with APS at gradient concentrations of $0 \mu \mathrm{g} / \mathrm{ml}$ and $30 \mu \mathrm{g} / \mathrm{ml}$ for $48 \mathrm{~h}$ and then harvested and counted. $1 \times 10^{6}$ cells were prepared for each sample. After washing twice using pre-cooled phosphate buffer solution, the cells were resuspended with an appropriate amount of binding buffer to a concentration of $(2-5) \times 10^{5}$ cells $/ \mathrm{ml}$. The cell suspension was added with $5 \mu \mathrm{l}$ of Annexin V-FITC and mixed gently. After $3 \mathrm{~min}$, it was added with $10 \mu \mathrm{l}$ of propidium iodide solution $(20 \mu \mathrm{g} / \mathrm{ml})$ and incubated for $10 \mathrm{~min}$ at room temperature in the dark, followed by mixing with an appropriate amount of binding buffer, detection and analysis on a flow cytometer.

\section{Detection of effect of APS on TLR4, MyD88 and NF- $\kappa B$ protein expression levels by western blotting:}

After normal H1299 cells and H1299 cells treated with APS $(30 \mu \mathrm{g} / \mathrm{ml})$ for $48 \mathrm{~h}$ were collected, the total protein was extracted. The protein concentration was determined using Bicinchoninic Acid (BCA) protein assay kits. A total of $20 \mu \mathrm{g}$ of proteins were loaded in each group and subjected to $12 \%$ sodium dodecyl sulfate-polyacrylamide gel electrophoresis. After electrophoresis, the proteins were transferred onto a Polyvinylidene Fluoride (PVDF) membrane using a semi-dry transfer method, blocked with $5 \%$ skim milk for $3 \mathrm{~h}$ and incubated with TLR4, MyD88 and NF- $\kappa \mathrm{B}$ antibodies $(1: 1000)$ at $4^{\circ}$ overnight.
With beta ( $\beta$ )-actin as a reference, the membrane was incubated with the corresponding secondary antibodies $(1: 20,000)$ at room temperature for $2 \mathrm{~h}$ and then washed 3 times with Tris Buffered Saline with Tween 20 (TBST), 10 min each time. After Enhanced chemiluminescence (ECL) was freshly prepared, the membrane was incubated for $3 \mathrm{~min}$, followed by X-ray exposure, development, fixation and imaging in a dark room. The band images were obtained with a scanner and Image-Pro Plus software was adopted to measure the gray values of TLR4, MyD88 and NF- $\kappa B$ bands to calculate the relative protein expression levels. The experiment was repeated three times.

\section{Statistical analysis:}

Statistical Package for the Social Sciences (SPSS) 19.0 software was adopted for statistical analysis. Measurement data were expressed by mean \pm standard deviation and t-test was employed for comparison between groups. One-way analysis of variance was applied for comparison among groups. $\mathrm{p}<0.05$ indicated that the difference was statistically significant.

\section{RESULTS AND DISCUSSION}

APS inhibited proliferation of H1299 cells. The cell proliferation and cytotoxicity assay was used to measure the effect of APS on the proliferation of H1299 cells and the results manifested that APS could significantly inhibit the proliferation of H1299 cells. APS at different concentrations could inhibit the proliferation of H1299 cells in a concentration-dependent manner at a certain time point, that is, the higher the concentration of APS, the stronger the inhibitory effect on H1299 cells. At the specific concentration and time points in this study, with the increase of APS concentration and duration of action, its inhibitory effect on H1299 cells was gradually enhanced (fig. 1).

APS inhibited migration of H1299 cells. In this study, APS at a concentration of $25 \mu \mathrm{g} / \mathrm{ml}$ close to the halfmaximal inhibitory concentration $\left(\mathrm{IC}_{50}\right)$ for $\mathrm{H} 1299$ cells, was subjected to wound healing assay. The results confirmed that after $24 \mathrm{~h}$, the migration rate of H1299 cells treated with $25 \mu \mathrm{g} / \mathrm{ml}$ APS was significantly lower than that blank control group, indicating that $25 \mu \mathrm{g} / \mathrm{ml}$ APS can significantly inhibit the migration of H1299 cells (fig. 2).

APS inhibited invasion of H1299 cells. The results of transwell chamber assay displayed that $\mathrm{H} 1299$ cells in control group could invade through Matrigel into the lower chamber through the membrane hole between the 


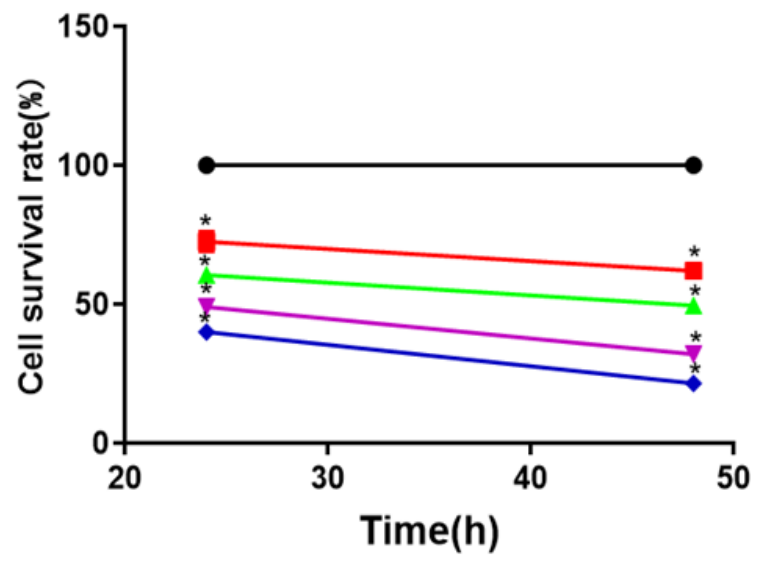

Fig. 1: Detection of effect of APS on proliferation of H1299 cells by proliferation and cytotoxicity assay, ${ }^{*} \mathrm{p}<0.05$ vs. control group at the same time point, $(\rightarrow)$ Control group; ( - - $) 25 \mu \mathrm{g} /$ ml APS; $(-) 50 \mu \mathrm{g} / \mathrm{ml}$ APS; $(-) 100 \mu \mathrm{g} / \mathrm{ml}$ APS; $(-),-200$ $\mu \mathrm{g} / \mathrm{ml}$ APS

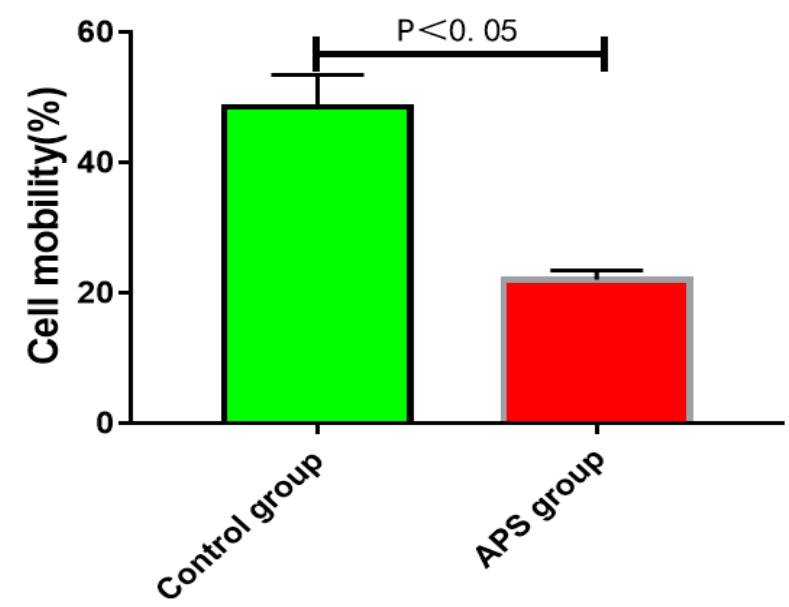

Fig. 2: Determination of effect of APS on migration ability of H1299 cells by wound healing assay

upper and lower chambers of transwell system. After treatment with $25 \mu \mathrm{g} / \mathrm{ml}$ APS, the number of H1299 cells invading through Matrigel into the lower chamber was significantly reduced, suggesting that $25 \mu \mathrm{g} / \mathrm{ml}$ APS can significantly inhibit the invasion ability of H1299 cells (fig. 3).

APS promoted apoptosis of $\mathrm{H} 1299$ cells. The results of cell apoptosis assay revealed that the apoptosis rate of H1299 cells treated with $25 \mu \mathrm{g} / \mathrm{ml}$ APS for $48 \mathrm{~h}$ was significantly higher than that in blank control group, demonstrating that $25 \mu \mathrm{g} / \mathrm{ml}$ APS can significantly promote the apoptosis of H1299 cells (fig. 4).

APS reduced MyD88, NF- $\mathrm{BB}$ and TLR4 protein expression levels in lung adenocarcinoma H1299 cells. Western blotting results indicated that MyD88, NF$\kappa \mathrm{B}$ and TLR4 protein expression levels in H1299 cells treated with APS $(25 \mu \mathrm{g} / \mathrm{ml})$ for $48 \mathrm{~h}$ were significantly lower than those in blank control group (fig. 5).
Lung cancer is the leading cause of cancer-related deaths worldwide. Most of lung cancer patients have local diffusion and/or distant metastasis when initially diagnosed. Although radical surgery is available for patients in the early stage, recurrence and metastasis

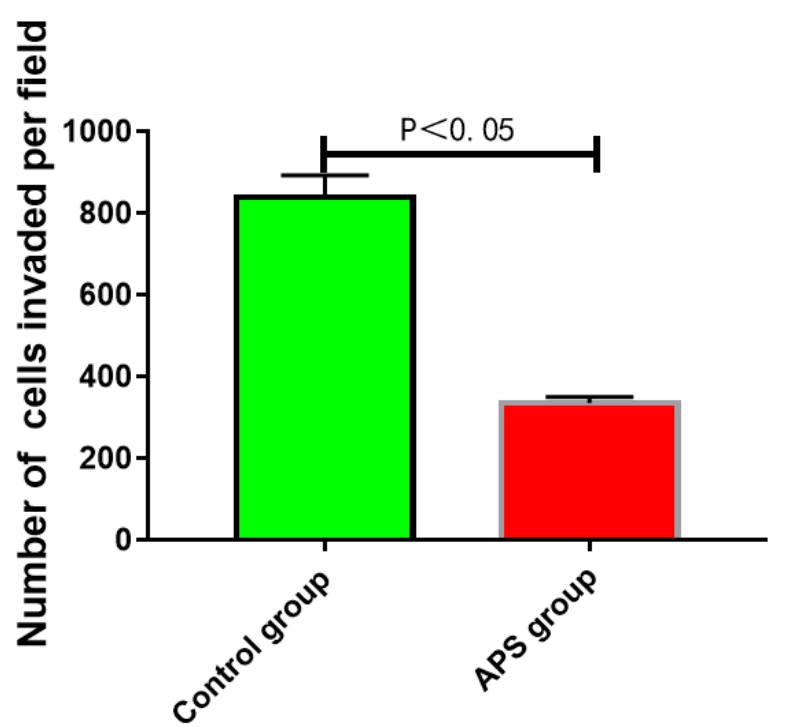

Fig. 3: Determination of effect of APS on invasion ability of H1299 cells by transwell assay

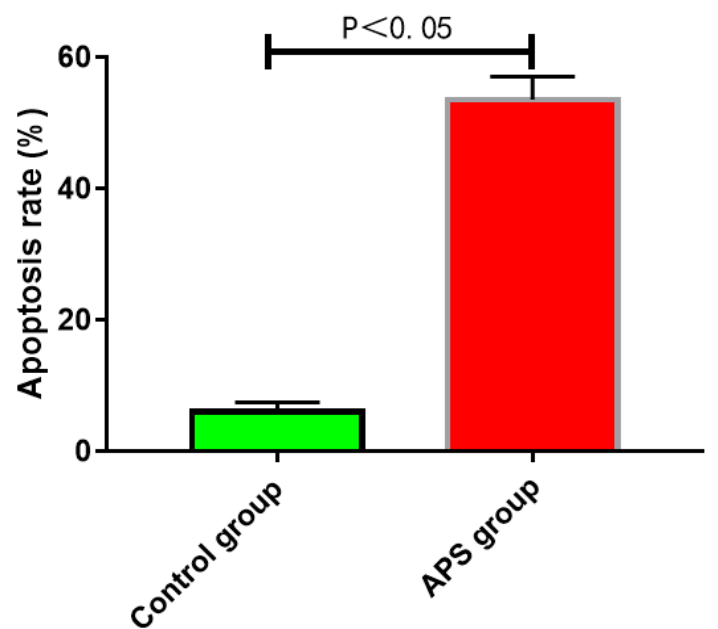

Fig. 4: Measurement of effect of APS on apoptosis ability of H1299 cells by flow cytometry

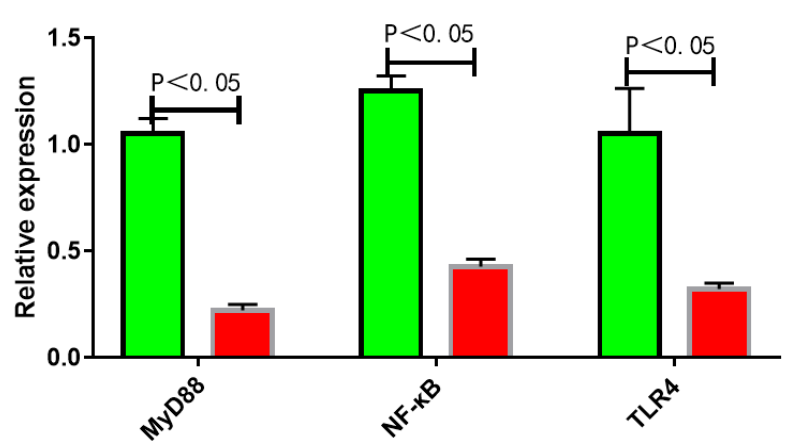

Fig. 5: Detection of effect of APS on MyD88, NF-кB and TLR4 protein expression levels in $\mathrm{H1299}$ cells by western blotting, ( $\square$ ) Control group; ( $\square$ ) APS group 
rates remain relatively high and the 5 y survival rate is less than $10 \%{ }^{[8]}$. At present, chemotherapy is still dominant in the treatment of lung cancer. However, resistance to conventional cytotoxic agents easily occurs due to their excessive damage to normal cells ${ }^{[9]}$. As recently reported, effective ingredients extracted from Chinese herbal medicine possess anti-tumor effects, bringing new hopes to tumor patients.

Astragalus is a commonly used traditional Chinese medicine and has been applied clinically ever since a long time ago. With advocating the modernization of traditional Chinese medicine nowadays, as the main active constituent of Astragalus, APS with anti-virus, anti-tumor, anti-aging, anti-radiation, anti-stress and anti-oxidation effects has been paid more attention ${ }^{[10,11]}$. APS-assisted chemotherapy, as reported, can enhance tumor suppression, reduce toxic and side effects, reinforce the body's cellular immune function and improve the quality of life of patients with tumors ${ }^{[12]}$. This study aimed to verify the inhibitory effect of APS on tumor cell invasion and metastasis and to explore its molecular mechanism. The results indicated that APS could significantly inhibit the proliferation of H1299 cells in a dose-dependent manner and APS $(25 \mu \mathrm{g} / \mathrm{ml})$ could inhibit the migration and invasion abilities and promote the apoptosis of H1299 cells, further revealing that APS may be a potential anti-lung cancer drug.

Tumor invasion and metastasis remains to be the major causes of death in cancer patients. The metastasis and recurrence rates of NSCLC rank at the forefront of primary malignancies. Therefore, identifying the mechanism of invasion and metastasis of lung cancer at the molecular level and investigating the prevention and treatment strategies are of great essentiality. Tumor invasion and metastasis is a complex process involving multiple stages which can be generalized into three steps from the molecular level, namely adhesion, protein degradation and migration. Tumor cells first adhere to extracellular matrix, vascular endothelium and target organs. Subsequently, the hydrolase is secreted to degrade and destroy extracellular matrix and capillary basement membrane. After breaking through the restriction, they infiltrate the surrounding tissues and organs or enter the blood circulation or lymphatic system, finally forming metastases ${ }^{[13,14]}$. At present, the effects of APS on the invasion and metastasis of malignant tumor cells are rarely reported. TLR figures prominently in the identification of pathogens and activation of innate immune system. As the first TLR protein identified, TLR4 can recognize LPS of Gram- positive bacteria. TLR4, MyD88 and NF- $\kappa$ B are the key molecules of the TLR4 signaling pathway. Once the TLR4/MyD88/NF- $\kappa$ B signaling pathway is activated, it will lead to T-helper 1 (Th1)/T-helper 2 (Th2) immune imbalance thus accelerating inflammation. The TLR4/ MyD88/NF- $\mathrm{kB}$ signaling pathway is mostly activated in inflammation and immune response, which is positively related to the proliferation and migration abilities of malignant tumor cells ${ }^{[15-18]}$. However, whether the inhibitory effect of APS on the proliferation of lung cancer cells is correlated with the TLR4/MyD88/NF- $\mathrm{BB}$ signaling pathway has not been elucidated yet. In this study, therefore, the changes in expressions of TLR4/ MyD88/NF- $\kappa \mathrm{B}$ signaling pathway-related proteins in H1299 cells were detected and the results indicated that MyD88, NF- $\kappa \mathrm{B}$ and TLR4 protein expression levels in lung adenocarcinoma H1299 cells treated with APS $(25 \mu \mathrm{g} / \mathrm{ml})$ for $48 \mathrm{~h}$ were significantly lower than those in blank control group.

In conclusion, APS can significantly inhibit the proliferation, migration and invasion and remarkably promote apoptosis of human lung adenocarcinoma H1299 cells cultured in vitro, and reduce MyD88, NF$\kappa \mathrm{B}$ and TLR4 protein expression levels in H1299 cells, indicating that inhibiting the proliferation, migration and invasion and inducing the apoptosis of H1299 cells may be related to the reduced expression levels of key proteins in the TLR4/MyD88/NF- $\mathrm{BB}$ signaling pathway in cells.

\section{Conflict of interests:}

The authors declared no conflict of interest.

\section{REFERENCES}

1. Cheng TY, Cramb SM, Baade PD, Youlden DR, Nwogu C, Reid ME. The international epidemiology of lung cancer: Latest trends, disparities and tumor characteristics. J Thorac Oncol 2016;11(10):1653-71.

2. Huang CY, Ju DT, Chang CF, Reddy PM, Velmurugan BK. A review on the effects of current chemotherapy drugs and natural agents in treating non-small cell lung cancer. Biomedicine 2017;7(4):23.

3. Sgambato A, Casaluce F, C Sacco P, Palazzolo G, Maione P, Rossi A, et al. Anti PD-1 and PDL-1 immunotherapy in the treatment of advanced non-small cell lung cancer (NSCLC): A review on toxicity profile and its management. Curr Drug Saf 2016;11(1):62-8.

4. Liu Y, Liu W, Li J, Tang S, Wang M, Huang W, et al. A polysaccharide extracted from Astragalus membranaceus residue improves cognitive dysfunction by altering gut microbiota in diabetic mice. Carbohydr Polym 2019;205:50012.

5. Liu H, Zhang G, Huang J, Ma S, Mi K, Cheng J, et al. Atractylenolide I modulates ovarian cancer cell-mediated immunosuppression by blocking MD-2/TLR4 complex- 
mediated MyD88/NF- $\kappa \mathrm{B}$ signaling in vitro. J Transl Med 2016;14(1):1-2.

6. Ding YF, Peng ZX, Ding L, Peng YR. Baishouwu extract suppresses the development of hepatocellular carcinoma via TLR4/MyD88/NF-кB pathway. Front Pharmacol 2019;10:389.

7. Long $\mathrm{T}$, Liu Z, Shang J, Zhou X, Yu S, Tian $\mathrm{H}$, et al. Polygonatum sibiricum polysaccharides play anti-cancer effect through TLR4-MAPK/NF- $\kappa B$ signaling pathways. Int J Biol Macromol 2018;111:813-21.

8. Alvarado-Luna G, Morales-Espinosa D. Treatment for small cell lung cancer, where are we now: A review. Transl Lung Cancer Res 2016;5(1):26-38.

9. Rizvi NA, Hellmann MD, Brahmer JR, Juergens RA, Borghaei $\mathrm{H}$, Gettinger $\mathrm{S}$, et al. Nivolumab in combination with platinum-based doublet chemotherapy for first-line treatment of advanced non-small cell lung cancer. J Clin Oncol 2016;34(25):2969-79.

10. Wei J, Li Y, Xu B, Yu J. Astragalus polysaccharides reverse gefitinib resistance by inhibiting mesenchymal transformation in lung adenocarcinoma cells. Am J Transl Res 2020;12(5):1640-57.

11. Huang X, Tang W, Lin C, Sa Z, Xu M, Liu J, et al. Protective mechanism of Astragalus polysaccharides against cantharidin-induced liver injury determined in vivo by liquid chromatography/mass spectrometry metabolomics. Basic Clin Pharmacol Toxicol 2021.

12. Xiong J, Jiang $\mathrm{B}$, Luo $\mathrm{Y}$, Zou J, Gao X, Xu D, et al.
Multifunctional nanoparticles encapsulating Astragalus polysaccharide and gold nanorods in combination with focused ultrasound for the treatment of breast cancer. Int $\mathrm{J}$ Nanomedicine 2020;15:4151-69.

13. Zheng $\mathrm{H}, \mathrm{Wu} \mathrm{X}$, Yin J, Wang $\mathrm{S}$, Li Z, You C. Clinical applications of liquid biopsies for early lung cancer detection. Am J Cancer Res 2019;9(12):2567-79.

14. Vitale C, D'Amato M, Calabrò P, Stanziola AA, Mormile M, Molino A. Venous thromboembolism and lung cancer: A review. Multidiscip Respir Med 2015;10(1):1-9.

15. Lin X, An X, Wang L, Zhang J, Abuduwaili A, Wang H, et al. Ainsliaea fragrans champ. Extract prevents cervicitis in $\mathrm{BALB} / \mathrm{c}$ mice and regulates MyD88-NF- $\mathrm{KB}$ signaling pathway in MALP-2-stimulated RAW264. 7 cells. J Ethnopharmacol 2021;269:113684.

16. Rathore M, Girard C, Ohanna M, Tichet M, Jouira RB, Garcia E, et al. Cancer cell-derived long pentraxin 3 (PTX3) promotes melanoma migration through a toll-like receptor 4 (TLR4)/NF$\kappa \mathrm{B}$ signaling pathway. Oncogene 2019;38(30):5873-89.

17. Gao Y, Han T, Han C, Sun H, Yang X, Zhang D, et al. Propofol regulates the TLR4/NF- $\kappa \mathrm{B}$ pathway through miRNA-155 to protect colorectal cancer intestinal barrier. Inflammation 2021;44:2078-90.

18. Xuemei L, Qiu S, Chen G, Liu M. Myrtenol alleviates oxidative stress and inflammation in diabetic pregnant rats via TLR4/ MyD88/NF- $\mathrm{B}$ signaling pathway. J Biochem Mol Toxicol 2021;35(11):e22904. 